\title{
GERAÇÃO DE RESÍDUOS RECICLÁVEIS NO MUNICÍPIO DE CAÇADOR-SC
}

Roger Francisco Ferreira de Campos ${ }^{1}$

Tiago Borga ${ }^{2}$

\begin{abstract}
RESUMO
Um dos principais problemas ambientais atualmente são os resíduos sólidos urbanos e medidas de controle e gestão são necessárias para o controle dos impactos ambientais ocasionados pelos resíduos sólido. O estudo foi realizado junto a Cooperativa Cidadania e Meio Ambiente e as empresas de reciclagem do município, no período de 01/01/2013 a 31/12/2013, onde foi aplicado a técnica de composição gravimétrica conforme NBR 10.007/04. Tendo um volume total amostrado de $2.602 .495,78 \mathrm{~kg} / \mathrm{ano}$, sendo um trabalho correspondente a toda área do município. Conforme levantado chegou 240.822,95 kg em janeiro, $233.634,37 \mathrm{~kg}$ em fevereiro, 219.155,3 kg em março, 219.155,3 kg em abril, 208.586,75 kg em maio, 187.469,51 kg em junho, 196.454,97 kg em julho, $196.074,00 \mathrm{~kg}$ em agosto, 189.068,27 kg em setembro, 198.913,48 kg em outubro, $216.272,66 \mathrm{~kg}$ em novembro e 234.449,65 kg em dezembro. Esses dados posteriormente serão utilizados no Plano Municipal Integrado de Gestão de Resíduos Sólidos do município de Caçador, impondo as diretrizes referentes aos resíduos sólidos.
\end{abstract}

Palavras-chave: Residuos Serviços de Saúde. Composição Gravimnétrica. Geração.

\section{ABSTRACT}

Among the solid waste health service wastes have a significant impact on the environment when improperly designed. The study was conducted in Pharmacies, Clinics and Veterinary Clinical Laboratory comprehensive municipality in the period from $01 / 11 / 2013$ to $02 / 12 / 2013$, getting a generation of $18,533.67 \mathrm{~kg} / \mathrm{month}$ of Clinical Analysis Laboratories, $3283.29 \mathrm{~kg} / \mathrm{month}$ in Veterinary Clinics and 6249.70 $\mathrm{kg} /$ month Pharmacies. According to the survey the study showed a generation of $4409.75 \mathrm{~kg} /$ month of biowaste, $10.787 .80 \mathrm{~kg} /$ month of chemical waste, 10787.80

\footnotetext{
${ }^{1}$ Engenheiro Ambiental, Especialista em Metodologia do Ensino Superior, Mestrando em Ciências Ambientais pela Universidade do Estadual de Santa Catarina - UDESC/CAV. E-mail: rogerffcampos@gmail.com.

2 Engenheiro Ambiental, Especialista em Gestão, Perícia e Auditoria Ambiental, Mestrando em Desenvolvimento e Sociedade pela Universidade Alto Vale do rio do Peixe - UNIARP. E-mail: tiagoborga@gmail.com.
} 
$\mathrm{kg} /$ month of recyclable waste, $7,167.33 \mathrm{~kg} /$ month of waste and 3,338 common 15 $\mathrm{kg} / \mathrm{month}$ of sharp punch waste. This data can further be used in the Integrated Municipal Plan Hunter municipal Waste Management, imposing guidelines relating to solid waste.

Keywords: Waste Health Services. Composition Gravimetric.

\section{INTRODUÇÃO}

Muitos resíduos descartados pela população brasileira possuem a possibilidade de ser reciclado, esses por sua vez quando não descartados pela coleta seletiva são descartados irregularmente em córregos ou em longo das vias públicas (SCHINEIDER; PHILIPPI, 2004; CAMPOS, 2013).

O manejo inadequado de resíduos sólidos de qualquer origem gera desperdícios, constitui ameaça constante à saúde pública e agrava a degradação ambiental, comprometendo a qualidade de vida das populações, especialmente nos centros urbanos de médio e grande porte (SANCHES et al., 2006).

Segundo Sanches et al., (2006) devido à falta de controle e manejo adequado os Resíduos Sólidos Urbanos (RSU) estão entre os maiores problemas ambientais da atualidade. A sua composição está relacionada com a situação socioeconômica e com as condições e hábitos de vida de uma determinada região.

O processo de gestão dos resíduos sólidos urbanos é um conjunto de ações normativas, operacionais, financeiras e de planejamento de uma administração municipal, ela é desenvolvida com base em critérios sanitários e econômicos para coletar, aproveitar, tratar e destinar os resíduos das áreas urbanas e rurais. Desta gestão, também participa toda a sociedade geradora, com a adesão de programas de educação ambiental, redução de materiais descartados e separação dos resíduos recicláveis (SISINNO; OLIVEIRA, 2000; GONÇALVES; DIAS, 2007).

Segundo Campos (2013) Caçador-SC sofre com pontos irregulares de resíduos sólidos e muito desses resíduos possui um alto potencial de reciclagem. $\mathrm{O}$ município possui uma cooperativa que realiza a triagem e posteriormente a reciclagem do material que é coletado na coleta seletiva. Porém, medidas socioambientais devem ser tomadas para uma gestão correta dos resíduos no município, sabendo que o processo possui muitas falhas. 
Assim, este trabalho tem como objetivo avaliar a quantidade de material que é reciclado no município de Caçador, no período de janeiro a dezembro de 2013 para complementar os dados do Plano Municipal Integrado de Gestão dos resíduos sólidos. Para essa determinação da geração anual foi realizado o levantado a geração de resíduos em impressas que realizam a reciclagem e em uma cooperativa que recolhe o material pela coleta seletiva no município de Caçador-SC.

\section{MATERIAIS E MÉTODOS}

O estudo foi realizado no Município de Caçador, localizado nas coordenas geográficas $26^{\circ} 46^{\prime} 07.5^{\prime \prime}$ S e $50^{\circ} 59^{\prime} 41.4^{\prime \prime}$ W, na região do Alto Vale do Rio do Peixe, a $400 \mathrm{~km}$ de Florianópolis. Compondo uma área $984,285 \mathrm{~km}^{2}$, possuindo uma população de 70,762 habitantes, segundo IBGE (2010). Sendo que 6.304 habitantes residem na área rural, representando 8,91\% e 64.431 habitantes na área urbana com 91,09\% em domicílios.

O estudo foi realizado no ano de 2013, onde foi encaminhado ofícios pela Fundação Municipal do Meio Ambiente - FUNDEMA solicitando o acesso nas empresas que realizam reciclagem e na Cooperativa Cidadania e Meio Ambiente COOCIMA que recebe o material reciclável da coleta seletiva do município, para realizar o levantamento foi aplicando à técnica de caracterização gravimétrica conforme NBR 10007/04, sendo que o município de Caçador possui 5 empresas recicladoras, além de uma Cooperativa, onde foram levantadas a geração de todas as classes de resíduos sólidos urbanos e rurais (papel, papelão, plástico, vidro, eletrônicos, alumínio, metal e ferro).

\section{RESULTADOS E DISCUSSÕES}

O município de Caçador-SC possui uma geração de $2.602 .495,78$ kg/ano em 2013, obtendo uma geração per capta de 36,77 kg/hab./ano, 3,06 kg/hab./mês e 0,101 kg/hab./dia (CAMPOS; BORGA, 2015).

A geração per capita de resíduos sólidos recicláveis e orgânicos no Brasil corresponde a $359 \mathrm{~kg} / \mathrm{hab}$./ano, sendo que a região sul gera 0,81 kg/hab./dia. 
(BRASIL, 2014).

Segundo Campos e Borga (2015) o valor reciclado que é produzido por cada habitante/dia no município de Caçador é de 1,39 kg/mês a partir de um estudo gravimétrico realizado no mês de agosto na cooperativa do município. Assim, mostrando uma geração per capta mais precisa com o presente estudo.

Gráfico 3. Porcentagem total de resíduos recicláveis gerados no mês amostrado;

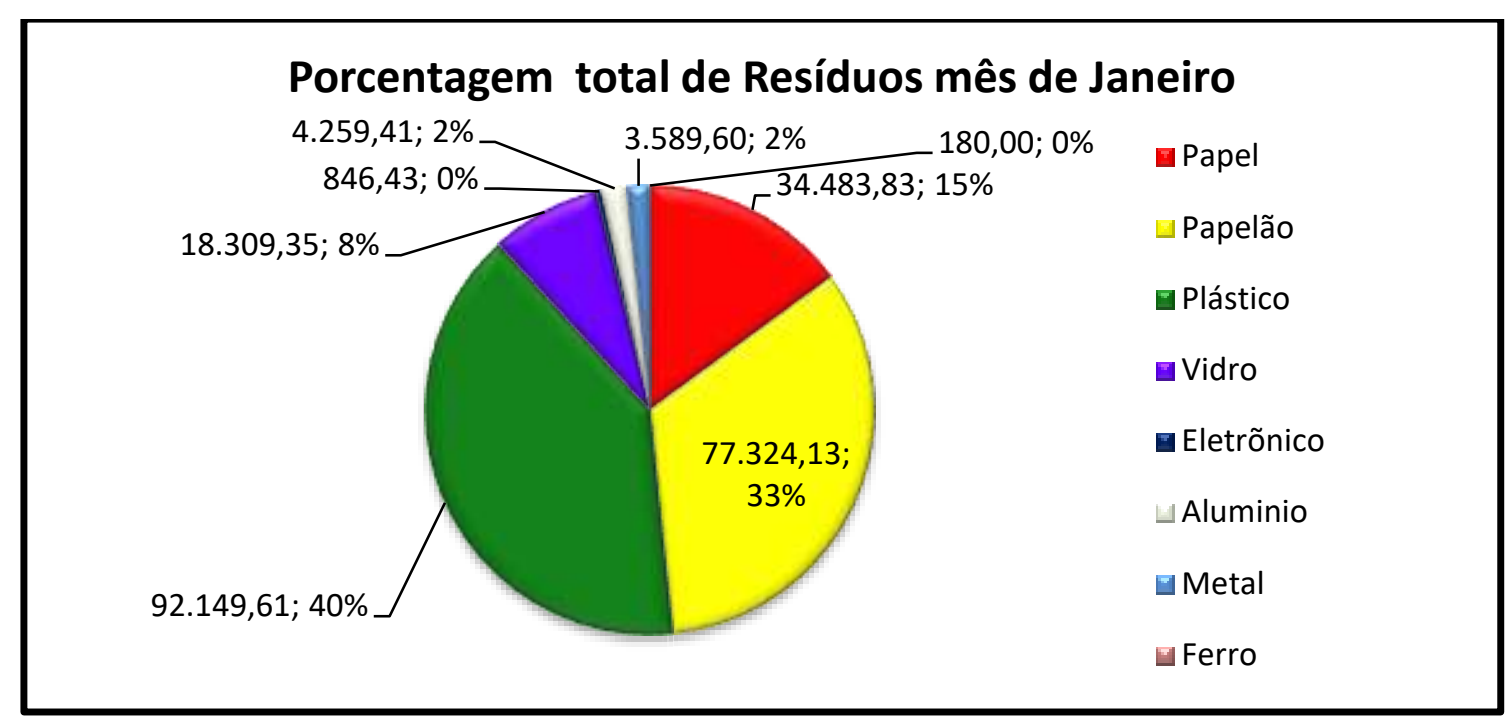

Fonte: (CAMPOS; BORGA, 2015).

O mês de janeiro corresponde a uma geração de $34.483,83 \mathrm{~kg}$ de papel, 77.324,13 kg de papelão, 92.149,61 de plástico, 18.309,35 kg de vidro, 846,43 kg de eletrônico, 4.259,41 kg de alumínio, 35.896,00 kg de metal e $180 \mathrm{~kg}$ de ferro, no total de $240.822,95 \mathrm{~kg} /$ mês.

Gráfico 4. Porcentagem total de resíduos recicláveis gerados no mês amostrado 


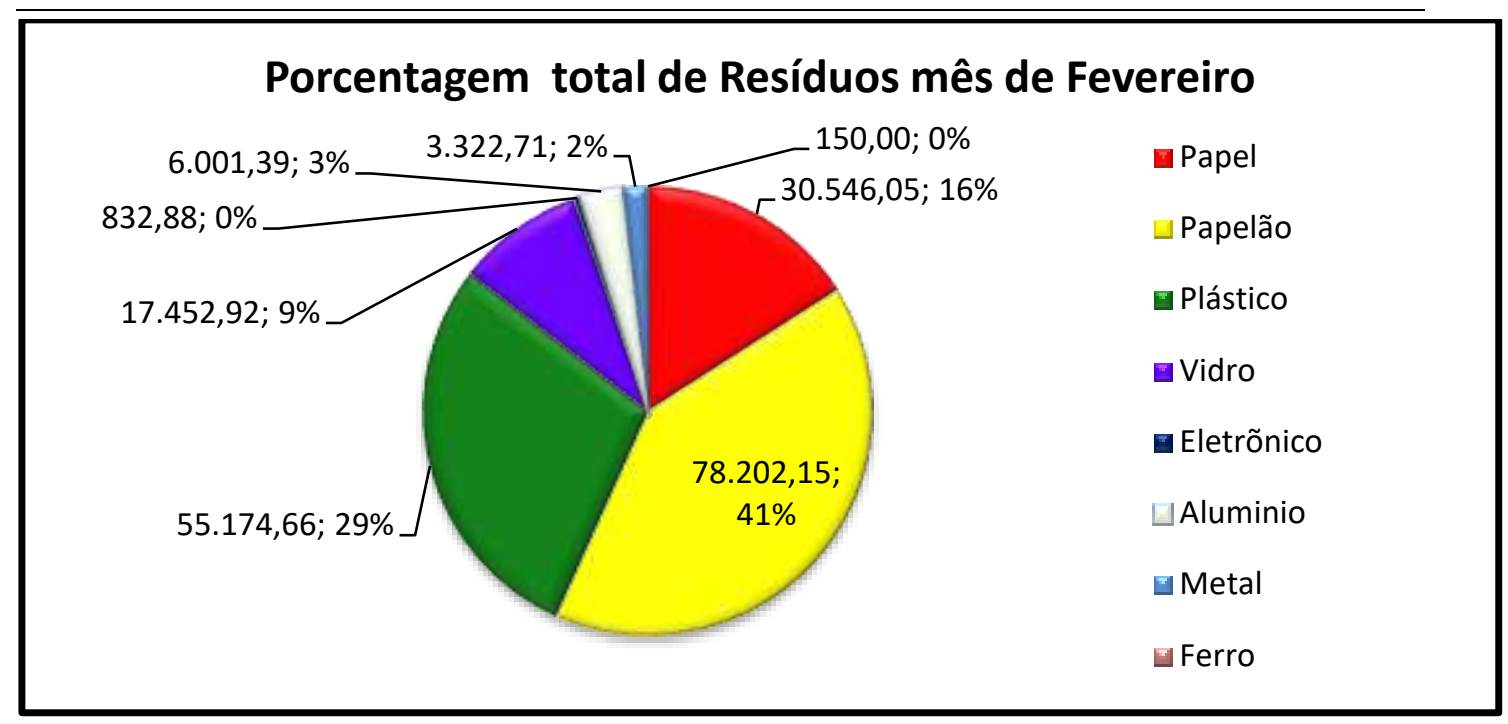

Fonte: (CAMPOS; BORGA, 2015).

O mês de fevereiro corresponde a uma geração de 30.546,05 kg de papel, $78.202,15 \mathrm{~kg}$ de papelão, 55.174,66 de plástico, 17.452,92 kg de vidro, 832,88 kg de eletrônico, 6.001,39 kg de alumínio, 3.322,71 kg de metal e $150 \mathrm{~kg}$ de ferro, no total de $233.634,37 \mathrm{~kg} / \mathrm{mês}$.

Gráfico 5. Porcentagem total de resíduos recicláveis gerados no mês amostrado

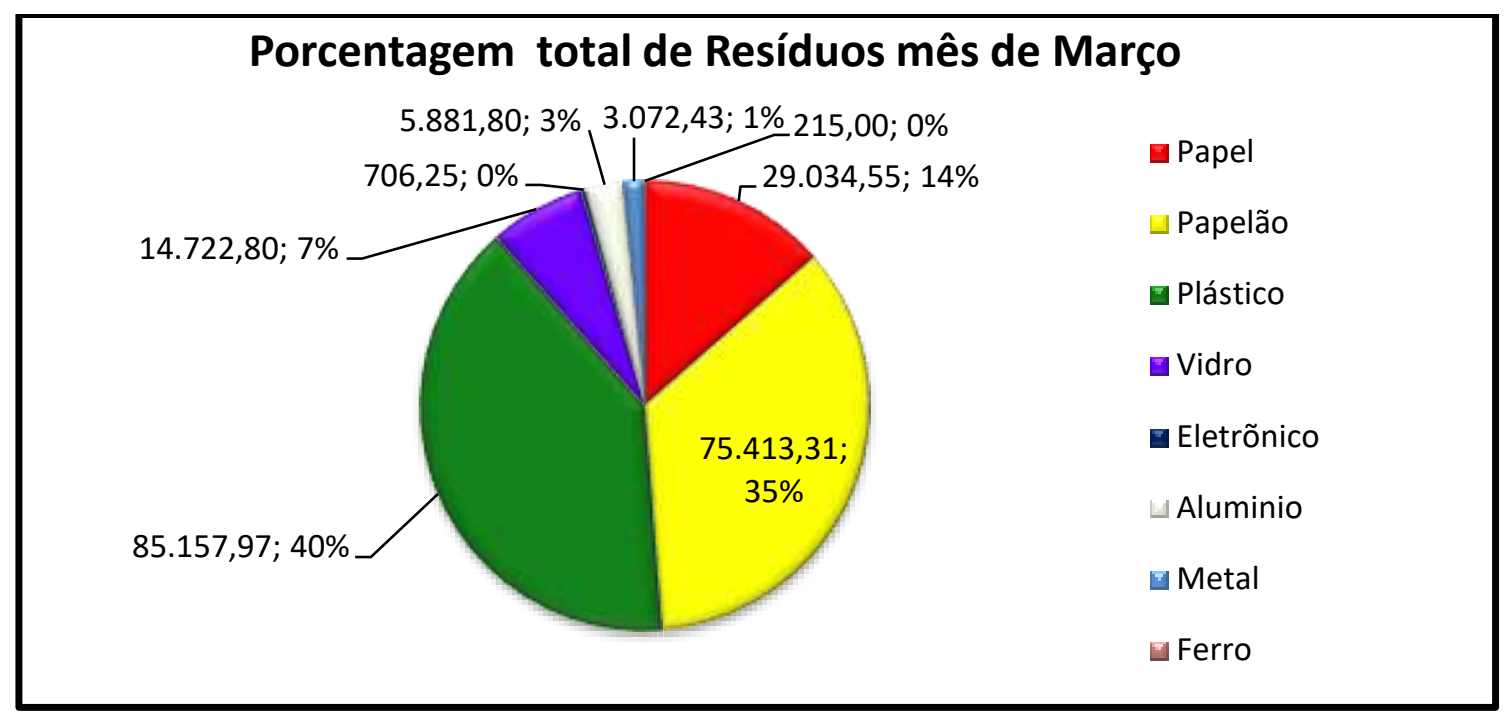

Fonte: (CAMPOS; BORGA, 2015).

O mês de março corresponde a uma geração de $29.034,55 \mathrm{~kg}$ de papel, $75.413,31 \mathrm{~kg}$ de papelão, 85.157,97 kg de plástico, 14.722,80 kg de vidro, 706,25 
kg de eletrônico, 5.881,80 kg de alumínio, 3.072,43 kg de metal e 215 kg de ferro, no total de $219.155,30 \mathrm{~kg} / \mathrm{mês}$.

Gráfico 6. Porcentagem total de resíduos recicláveis gerados no mês amostrado

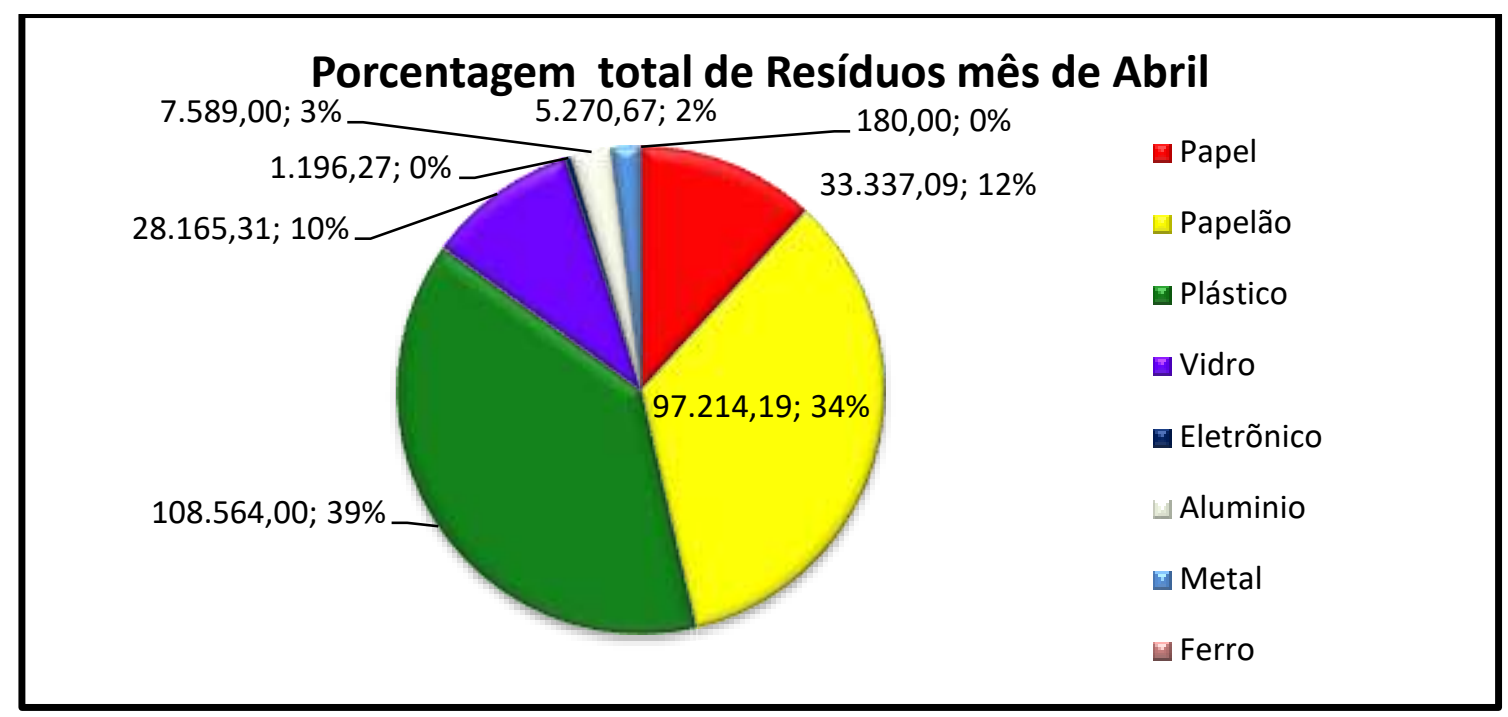

Fonte: (CAMPOS; BORGA, 2015).

O mês de abril corresponde a uma geração de $33.337,12 \mathrm{~kg}$ de papel, 97.214,190 kg de papelão, $108.564,00 \mathrm{~kg}$ de plástico, 28.165,31 kg de vidro, $1.196,27 \mathrm{~kg}$ de eletrônico, 7.589,00 kg de alumínio, 5.270,67 kg de metal e $180 \mathrm{~kg}$ de ferro, no total de $281.597,01 \mathrm{~kg} / \mathrm{mês}$.

Gráfico 7. Porcentagem total de resíduos recicláveis gerados no mês amostrado

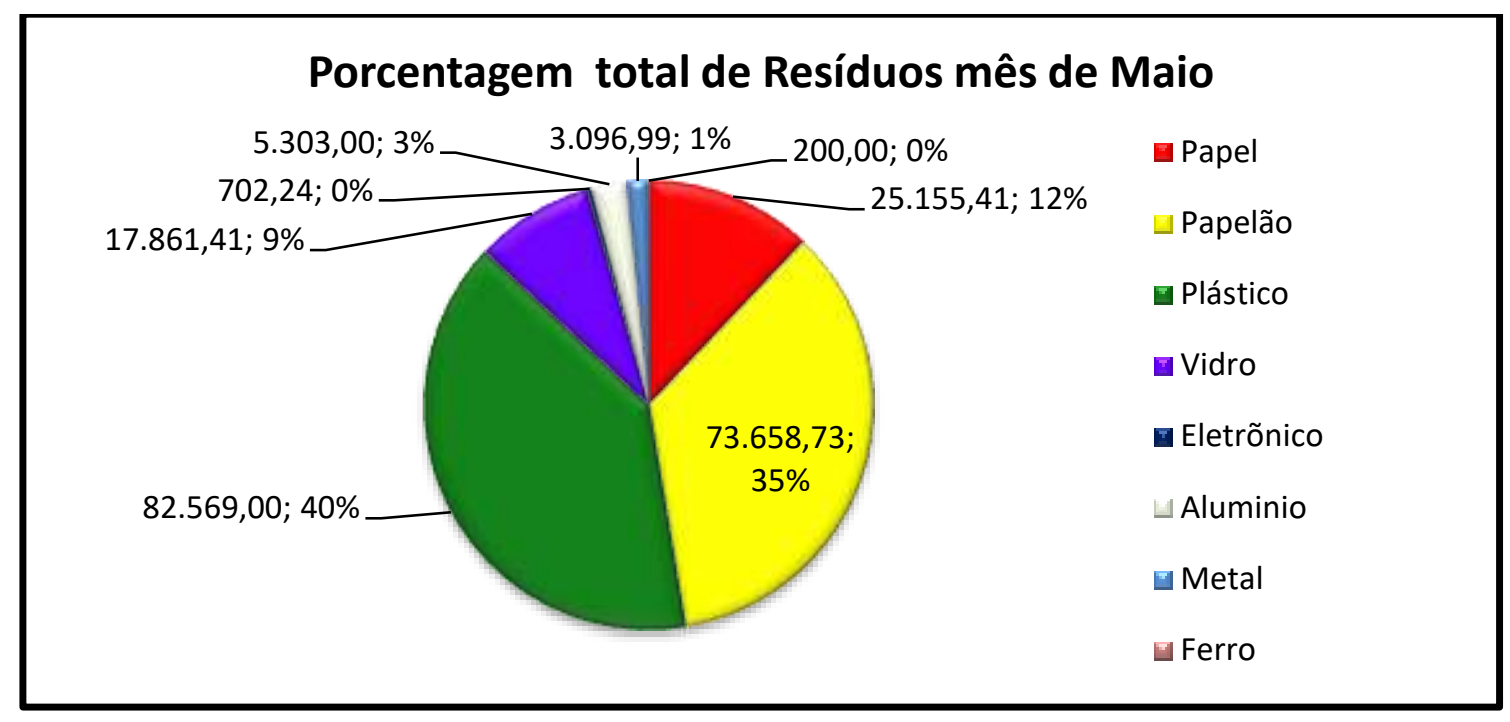

Fonte: (CAMPOS; BORGA, 2015). 
O mês de maio corresponde a uma geração de $25.155,41 \mathrm{~kg}$ de papel, $73.658,73 \mathrm{~kg}$ de papelão, 82.569,00 de plástico, $17.861,41 \mathrm{~kg}$ de vidro, 702,24 kg de eletrônico, 5.303,00 kg de alumínio, 3.096,99 kg de metal e $200 \mathrm{~kg}$ de ferro, no total de $208.586,75 \mathrm{~kg} / \mathrm{mês}$.

Gráfico 8. Porcentagem total de resíduos recicláveis gerados no mês amostrado

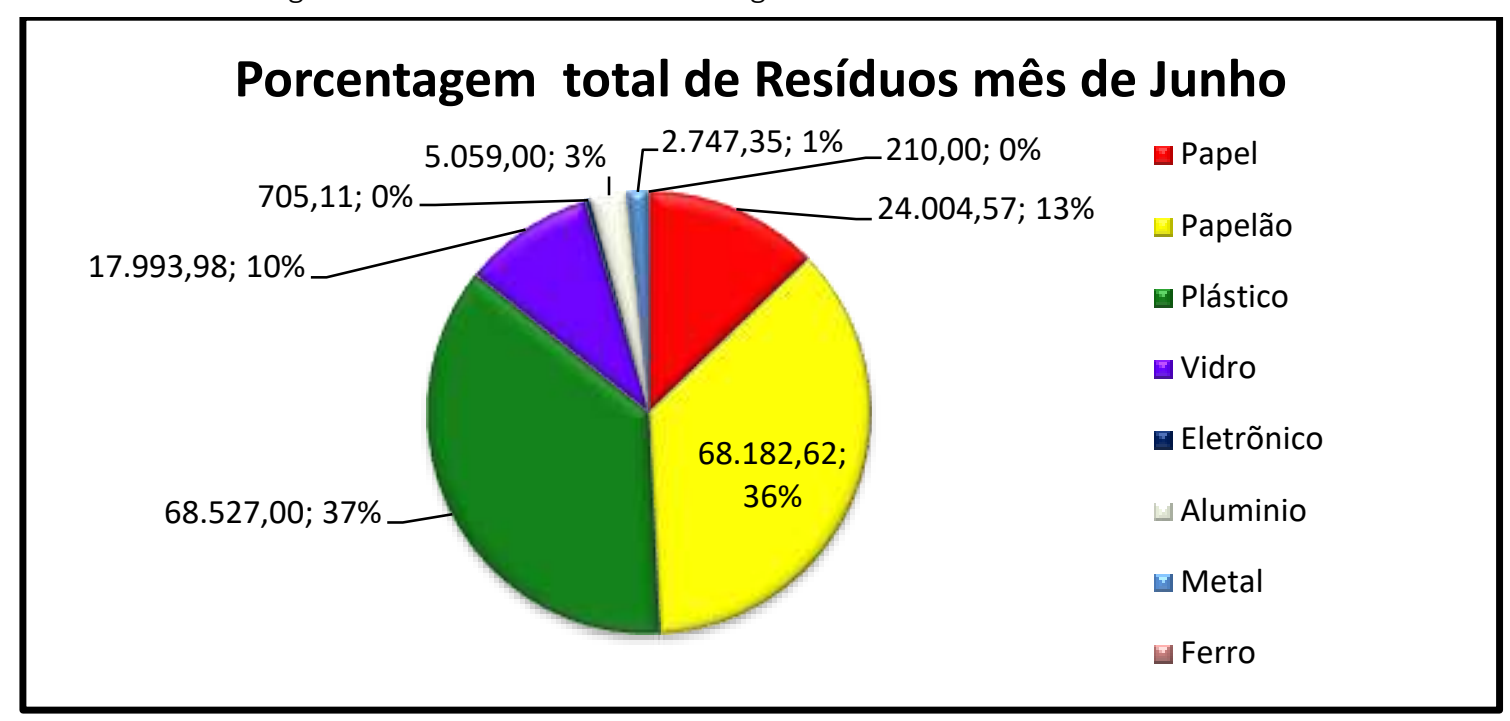

Fonte: (CAMPOS; BORGA, 2015).

O mês de junho corresponde a uma geração de $24.004,57 \mathrm{~kg}$ de papel, 68.182,62 kg de papelão, 68.527,00 de plástico, 17.993,98 kg de vidro, 705,11 kg de eletrônico, 5.059,00 kg de alumínio, 2.747,35 kg de metal e $210 \mathrm{~kg}$ de Ferro, no total de $187.469,51 \mathrm{~kg} / \mathrm{mês}$.

Gráfico 9. Porcentagem total de resíduos recicláveis gerados no mês amostrado 


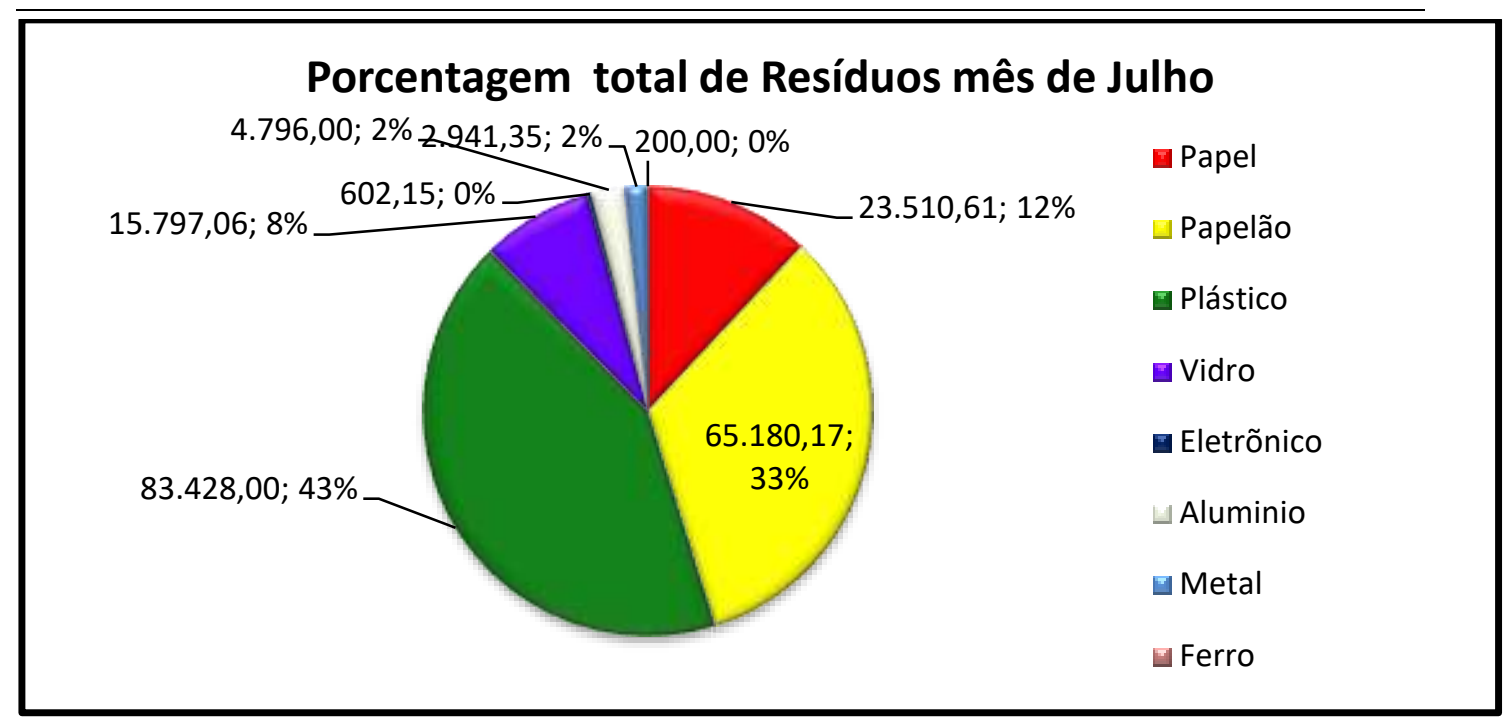

Fonte: (CAMPOS; BORGA, 2015).

O mês de julho corresponde a uma geração de 23.510,61 kg de papel, 65.180,17 kg de papelão, 83.248,00 de plástico, 15.797,00 kg de vidro, 802,15 kg de eletrônico, $4.796 \mathrm{~kg}$ de alumínio, 2.941,35 kg de metal e $200 \mathrm{~kg}$ de ferro, no total de $196.454 .97 \mathrm{~kg} / \mathrm{mês}$.

Gráfico 10. Porcentagem total de resíduos recicláveis gerados no mês amostrado

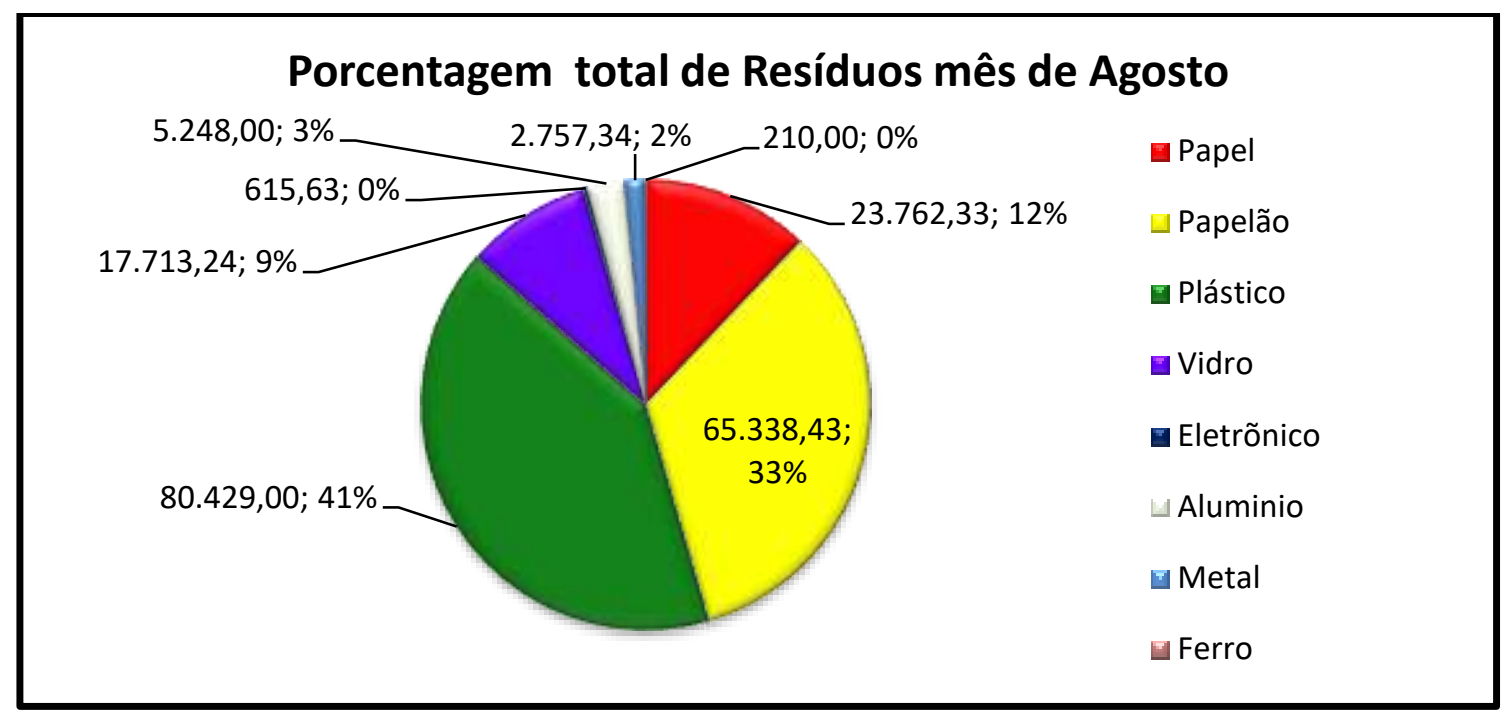

Fonte: (CAMPOS; BORGA, 2015).

O mês de agosto corresponde a uma geração de $23.762,33 \mathrm{~kg}$ de papel, $65.338,43 \mathrm{~kg}$ de papelão, 80.429,00 de plástico, 17.713,24 kg de vidro, 615,63 kg 
de eletrônico, 5.248,00 kg de alumínio, 2.757,34 kg de metal e $210 \mathrm{~kg}$ de ferro, no total de $196.074,00 \mathrm{~kg} / \mathrm{mês}$.

Gráfico 11. Porcentagem total de resíduos recicláveis gerados no mês amostrado;

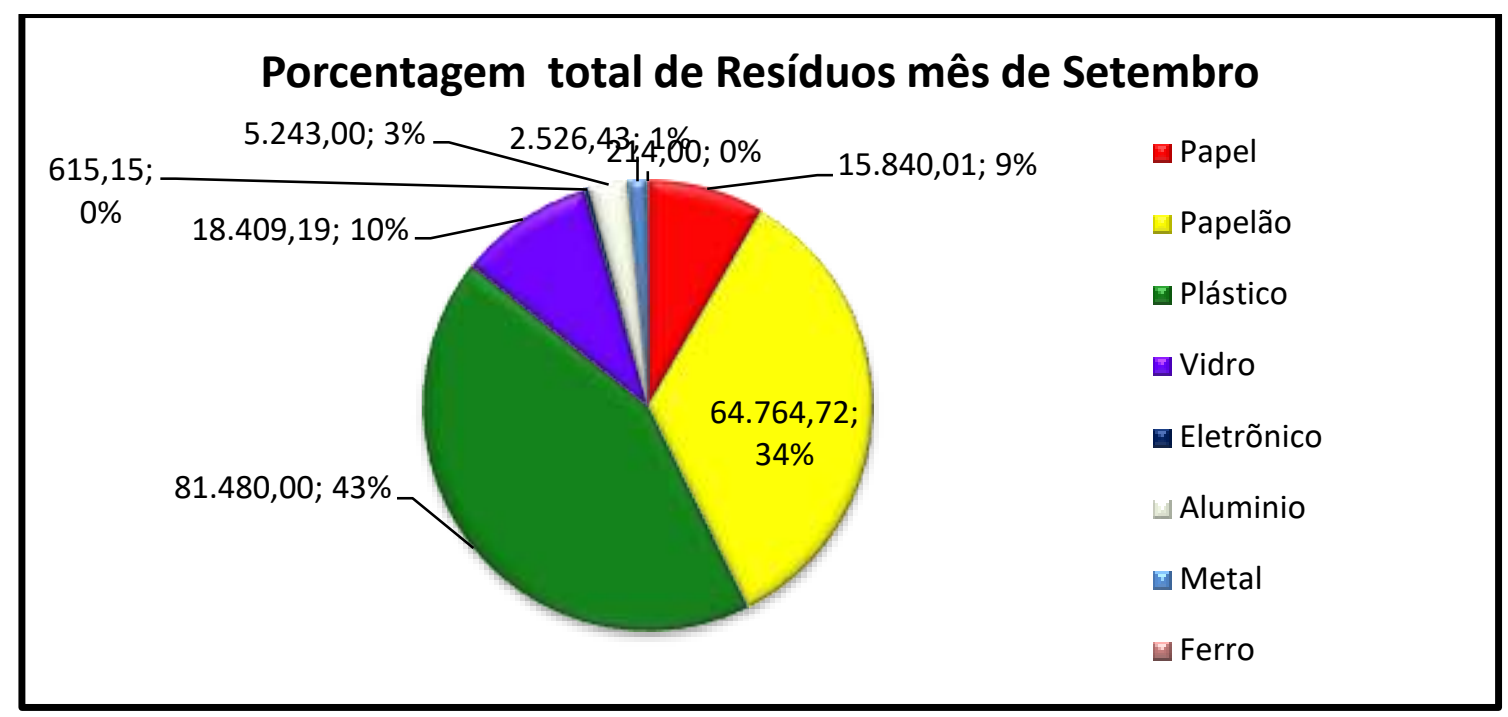

Fonte: (CAMPOS; BORGA, 2015).

O mês de setembro corresponde a uma geração de 15.840,00 kg de papel, $64.764,72 \mathrm{~kg}$ de papelão, 81.480,00 de plástico, 18.409,19 kg de vidro, 615,15 kg de eletrônico, 5.243,00 kg de alumínio, 2.526,43 kg de metal e 214 kg de ferro, no total de $189.913,48 \mathrm{~kg} / \mathrm{mês}$.

Gráfico 12. Porcentagem total de resíduos recicláveis gerados no mês amostrado

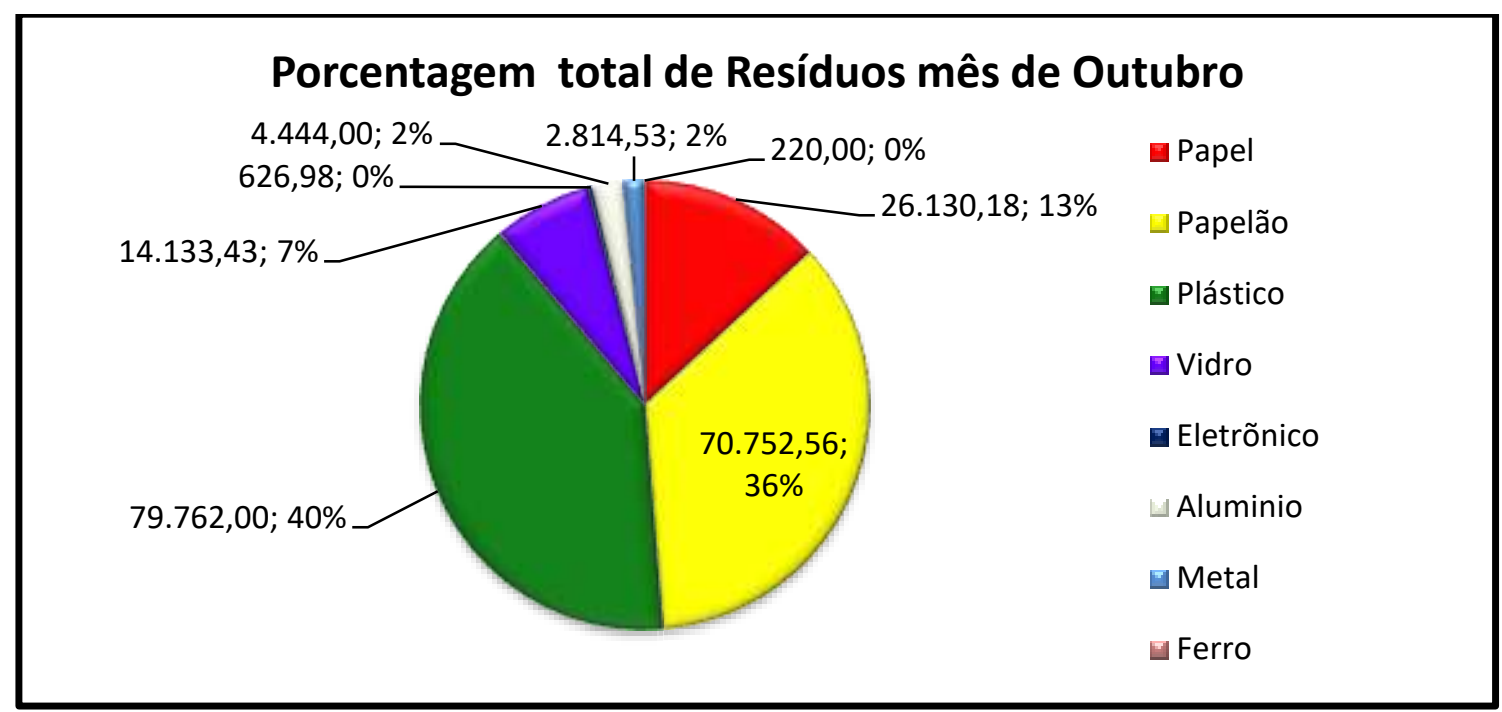

Fonte: (CAMPOS; BORGA, 2015). 
O mês de outubro corresponde a uma geração de 26.130,18 kg de papel, $70.752,56 \mathrm{~kg}$ de papelão, $79.762,00$ de plástico, $14.133,43 \mathrm{~kg}$ de vidro, 626,983 kg de eletrônico, 4.444,00 kg de alumínio, 2.814,53 kg de metal e $220 \mathrm{~kg}$ de ferro, no total de $198.943,48 \mathrm{~kg} / \mathrm{mês}$.

Gráfico 13. Porcentagem total de resíduos recicláveis gerados no mês amostrado

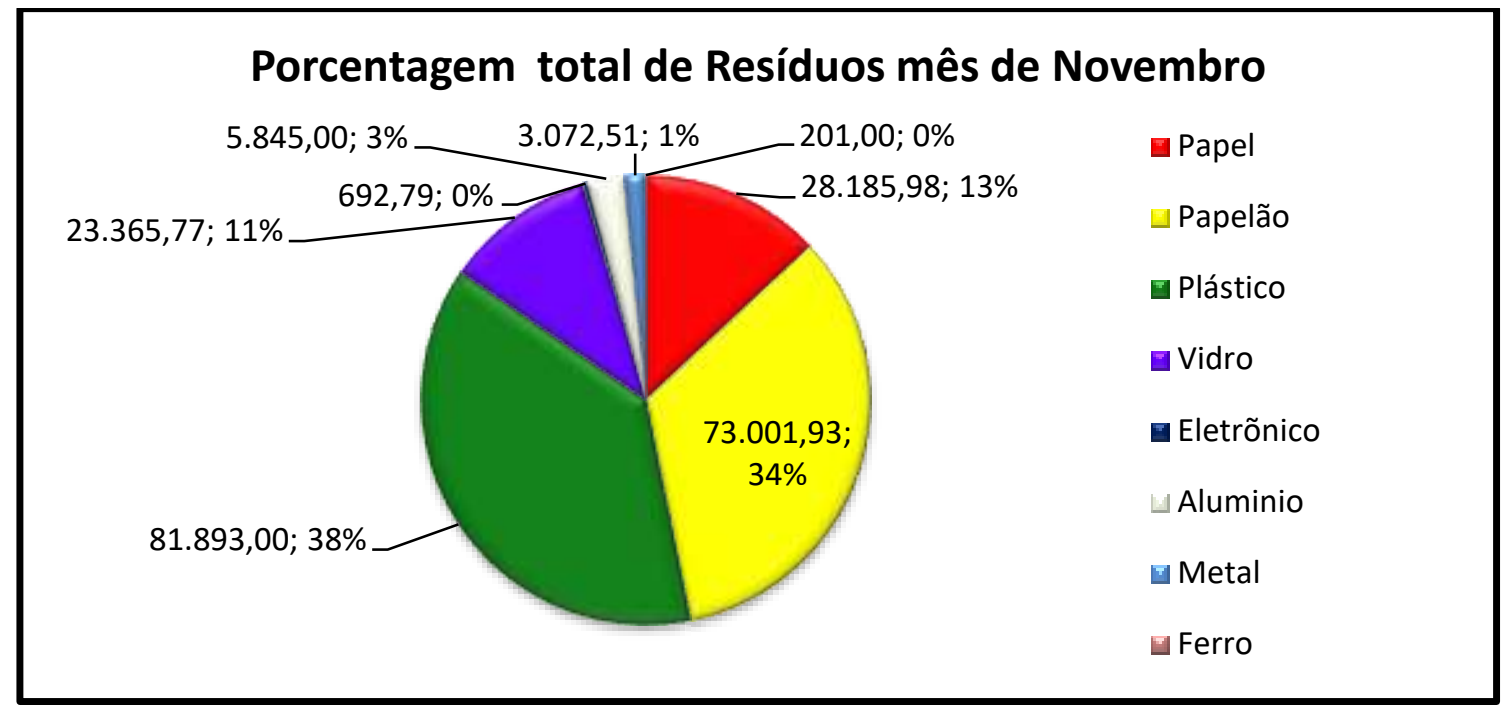

Fonte: (CAMPOS; BORGA, 2015).

O mês de novembro corresponde a uma geração de $28.185,98 \mathrm{~kg}$ de papel, 73.001,93 kg de papelão, 81.893,00 de plástico, 23.365,77 kg de vidro, 692,79 kg de eletrônico, 5.845,00 kg de alumínio, 3.072,51 kg de metal e $201 \mathrm{~kg}$ de ferro, no total de $216.272,66 \mathrm{~kg} / \mathrm{mês}$.

Gráfico 14. Porcentagem total de resíduos recicláveis gerados no mês amostrado 


\section{Porcentagem total de Resíduos mês de Dezembro}

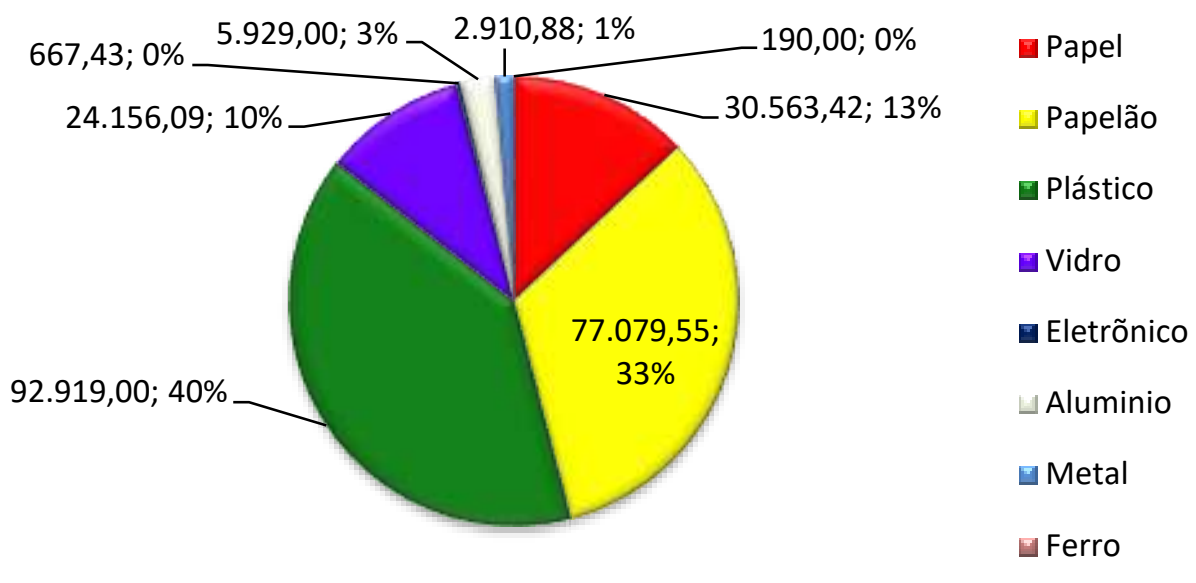

Fonte: (CAMPOS; BORGA, 2015).

O mês de dezembro corresponde a uma geração de $30.563,42 \mathrm{~kg}$ de papel, 77.079,33 kg de papelão, 92.919,00 de plástico, 24.156,09 kg de vidro, 667,43 kg de eletrônico, 5.929,00 kg de alumínio, 2.910,88 kg de metal e 190 kg de ferro, no total de $234.449,65 \mathrm{~kg} / \mathrm{mês}$.

O estudo mostra uma geração de 240.822,95 kg em janeiro, 233.634,37 kg em fevereiro, 219.155,3 kg em março, 219.155,3 kg em abril, 208.586,75 kg em maio, 187.469,51 kg em junho, 196.454,97 kg em julho, 196.074,00 kg em agosto, $189.068,27 \mathrm{~kg}$ em setembro, 198.913,48 kg em outubro, 216.272,66 kg em novembro e 234.449,65 kg em dezembro no ano de 2013.

Segundo Campos e Lima (2015), em um estudo de gestão de resíduos sólidos em um supermercado mostra que os meses que possui feriados de natal, carnaval, virada de ano e dia das mães o varejo do município de Caçador realiza mais compras de produtos, assim tendo uma maior gerações de resíduos recicláveis, onde o supermercado mostrando uma geração de 1.673,41 kg/mês em janeiro, $1.011,28 \mathrm{~kg} / \mathrm{mês}$ em fevereiro, 1.076,44 kg/mês em março, 1.167,67 $\mathrm{kg} / \mathrm{mês}$ em abril, 1.110,00 kg/mês maio, 937,69 em junho, 1.074,70 kg/mês em julho, $1094,27 \mathrm{~kg} / \mathrm{mês}$ em agosto, 936,53 kg/mês em setembro, 1.402,50 kg/mês em outubro, $1.442,14 \mathrm{~kg} / \mathrm{mês}$ em novembro e $1.442,61 \mathrm{~kg} / \mathrm{mês}$ em Dezembro.

A cooperativa que realiza reciclagem no município de Caçador possui uma geração $10,538 \%$ de papel, 22,869\% de papelão, 7,647\% de Tetra Pack, 3,048\% 
metal, 2,961\% de alumínio, 9,885\% de vidro, 11,169\% de plástico flexível, 13,150\% de plástico duro, 6,862\% de PET, 2,942\% de orgânico, 0,499\% de isopor, 0,643\% de eletrônico, 0,566\% de lâmpadas, $0,420 \%$ de pilhas, 3,242\% de rejeito e 3,559\% de sanitário. Esses componentes representaram $88,928 \%$ da porção do RSU destinado a COOCIMA que pode ser reciclada. Sendo o restante, 2,942\% composto de matéria orgânica que também é passível de reaproveitamento através da compostagem, 6,801\% composto de rejeitos e 0,986\% de outros materiais passiveis de logística reversa (CAMPOS; BORGA, 2015).

A geração dos resíduos sólidos urbanos no Brasil em 2011 corresponde à $13,1 \%$ ou 7.409 .603 t/ano de (papel, papelão e tetra pack), $13,5 \%$ ou 7.635 .851 t/ano de (plástico) de um total de 56.561.856 t/ano (ABRELPE, 2011).

Segundo Machado e Guadagnin (2008), o município de Criciúma-SC (192.308 habitantes) apresentou uma geração de 67\% de papel, 22,83 de plástico, $9 \%$ de vidro e $0,69 \%$ de metal no período de um ano, correspondente a área urbana. Comparando Criciúma-SC com município de Caçador, o município do presente estudo é mais seletivo no seu processo de reciclagem, por isso apresenta um valor inferior com plástico, papel e metal. Porém com vidro apresenta uma porcentagem maior de $1 \%$.

A caracterização do material da coleta seletiva do município de Florianópolis-SC compõe uma geração de $23 \%$ de papelão, 26\% de papel misto, $9 \%$ de papel branco, $3 \%$ de plástico mole, $9 \%$ de plástico duro, $4 \%$ de ferro, $0 \%$ de alumínio, $11 \%$ de vidro e $15 \%$ de rejeito (COMCAP, 2009).

Campos (2015) e Almeida (2012) citam que 23,95\% do material que está sendo destinado ao aterro é passível de reciclagem correspondendo a 2.737,23 toneladas de material com destinação imprópria.

Segundo Campos e Borga (2015) os resíduos amostrados em seu levantamento gravimétrico, são destinados a COOCIMA 10,73\% de materiais não passiveis de reciclagem como orgânicos, rejeito e sanitários, correspondendo a 132,73 toneladas. As questões das diretrizes dos resíduos como orgânico e reciclável, mostram que o município ainda precisa melhor seu processo de reciclagem e destinação dos resíduos. Porém, necessita de um melhoramento na gestão pública dos resíduos sólidos para que o município de Caçador se torne uma cidade modelo no processo de destinação correta de resíduos como reciclagem. 
Segundo Campos e Borga (2015) o município precisa de um trabalho contínuo de educação ambiental com ênfase na estruturação do programa de coleta seletiva, buscando modificar o hábito da população referente ao descarte de resíduos sólidos, pois se observa no estudo apresentado que cerca de 10,98\% do material coletado não são passiveis de reciclagem.

A partir do ano de 2012, Caçador-SC está passando por mudança referente aos resíduos, no qual está sendo um assunto altamente tratadas entre as entidades públicas e privadas. Com a competência do Plano Municipal de Gestão Integrada dos Resíduos Sólidos, busca-se o melhor caminho para que os resíduos que antes não eram reciclados, possam ter uma destinação correta com reciclagem e compostagem, ou a implantação de triagem no aterro sanitário do município (CAMPOS; BORGA, 2015).

\section{CONSIDERAÇÕES FINAIS}

Os dados obtidos permitem concluir a geração dos resíduos nos meses do estudo são: janeiro de 240.822,95 kg, 233.634,37 kg em fevereiro, 219.155,3 kg em março, 219.155,3 kg em abril, 208.586,75 kg em maio, 187.469,51 kg em junho, $196.454,97 \mathrm{~kg}$ em julho, $196.074,00 \mathrm{~kg}$ em agosto, 189.068,27 kg em setembro, $198.913,48 \mathrm{~kg}$ em outubro, 216.272,66 kg em novembro e 234.449,65 kg em dezembro, a partir do valor amostrado $2.602 .495,78 \mathrm{~kg} / \mathrm{ano}$.

O trabalho precisa de um acompanhamento continuo para melhor gestão dos resíduos sólidos urbanos no município de Caçador, sabendo que conforme o aumento da população maior a geração dos resíduos sólidos.

Esse estudo será de utilidade para o Plano Municipal de Gestão Integrada dos Resíduos Sólidos, no qual contribuirá para os dados e as diretrizes referente aos resíduos sólidos recicláveis. Sendo assim, este trabalho oferece informações sobre o potencial dos resíduos recicláveis e a quantidade de resíduo gerado em todo o município de Caçador-SC.

\section{REFERÊNCIAS}

ALMEIDA, R. G. Estudo de geração de resíduos sólidos domiciliar urbanos no 
município de Caçador-SC, Á partir caracterização física e composição gravimétrica. Revista Engenharias e Inovação Tecnológica- IGNIS, p. 71-92, 2012.

Abrelpe (2011). Panorama dos Resíduos Sólidos no Brasil 2011. Disponível em: http://www.abrelpe.org.br/panorama_apresentacao.cfm. Acesso em: 18 de maio de 2015 .

Abrelpe (2012). Panorama dos Resíduos Sólidos no Brasil 2012. Disponível em: http://www.abrelpe.org.br/panorama_apresentacao.cfm. Acesso em: 18 de maio de 2015.

BRASIL. Ministério da Fazenda. Economia brasileira em perspectiva. Disponível em: http://www. fazenda.gov.br/portugues/docs/perspectiva-economia-brasileira/ edicoes/Economia-Brasileira-Em-Perpectiva-Jun-Jul10.pdf. Acesso em: 8 de outubro de 2014.

Companhia Melhoramentos da Capital - COMCAP. Gestão dos Resíduos Sólidos Urbanos do Município de Florianópolis, Florianópolis, p. 148-149, 2000.

CAMPOS, R. F. F.; LIMA, C. Sustentabilidade através de remanejo de resíduos com prática de gestão ambiental implantado no supermercado cereal. Revista Engenharias e Inovação Tecnológica- IGNIS, v.3, n.1, p. 25-44, 2015.

CAMPOS, R. F. F. Fundema: Perimetral Norte SC-350 esta como pontos irregulares de descarte de resíduos. Disponível em: http://fundemacacador.blogspot.com.br/. Acesso em: 29 de julho de 2013.

CAMPOS, R. F. F. Meio Ambiente: Estudo da Fundema relata o que os Caçadorenses reciclam. Disponível em:

http://www.cacador.sc.gov.br/portalhome/index.php/noticias/fundema/2441meio-ambiente. Acesso em: 29 de julho de 2013.

GONÇALVES, B.B.; DIAS, J.F.. Resíduos Domiciliares Recicláveis: Prospecção para cidades de médio porte. OBSERVATORIUM: Revista Eletrônica de Geografia, v.1, n.1, p.84-104, 2007.

GUADAGNIN, M.R.; MACHADO, M.G. Análise da composição gravimétrica dos resíduos sólidos urbanos recicláveis da Cooperativa Trabalhadores de Materiais Recicláveis em Criciúma - CTMAR, do estado de Santa Catarina - Brasil. In: Simpósio Internacional de Qualidade Ambiental. 6., 2008. Porto Alegre. Anais... Porto Alegre: ABES, 2008. 
SANCHES, S.N.; SILVA C.H.T.P.; VASPA, I.C.G.; VIEIRA, E.M.. A importância da Compostagem para a educação Ambiental nas Escolas. Química Nova na Escola. São Paulo: Sociedade Brasileira de Química. № 23. Maio de 2006. P. 10-19. 2006.

SISINNO, C. L. S.; OLIVEIRA, R. M.. "Impacto Ambiental dos Grandes Depósitos de Resíduos Urbanos e Industriais". In: Sisinno, C. L. S., Oliveira, R. M. (org.), Resíduos Sólidos, Ambiente e Saúde: uma Visão Multidisciplinar, 1a ed, capítulo 1, Rio de Janeiro, Editora Fiocruz. 2000.

SCHINEIDER, D.M.; PHILIPPI, A.Jr.,. Gestão pública de resíduos da construção civil no município de São Paulo. Ambiente Construído, Porto Alegre, v. 4, n. 4, p. 21-32, out./dez. 2004. 